Краткие сообщения

05

\title{
Магнитополевое усиление пиннинга вихрей на фрактальных границах кластеров высокотемпературных сверхпроводников
}

\author{
(С) М.А. Васютин, Н.Д. Кузьмичев, Д.А. Шилкин \\ Мордовский государственный университет им. Н.П. Огарёва, \\ 430005 Саранск, Россия \\ e-mail: vasyutinm@mail.ru
}

(Поступило в Редакцию 7 июня 2017 г.)

\begin{abstract}
Изучено влияние фрактальности границ кластеров нормальной фазы меднооксидного высокотемпературного сверхпроводника YВСО на крип магнитного потока. Предложена модель зависимости напряжения, обусловленного крипом потока, от магнитного поля для разных транспортных токов. Экспериментальные зависимости аппроксимированы экспоненциально-гиперболической функцией с токовым параметром. Найдена эмпирическая магнитополевая зависимость фрактальной размерности границ кластеров ҮВСО. Определены значения напряженности магнитного поля и фрактальной размерности, при которых начинается проникновение вихрей в гранулы образцов. Вычислен индекс связности путей срыва вихрей на пороге перколяции.
\end{abstract}

DOI: $10.21883 / J T F .2018 .02 .45427 .2377$

Границы различных областей в образцах слабосвязанных сверхпроводников играют важную роль, приводя как к уменьшению, так и к увеличению критического тока. При этом сеть слабых связей имеет фрактальную структуру как во всем объеме образца, так и на границах различных дефектов или включений. Фрактальные свойства были обнаружены во многих меднооксидных высокотемпературных сверхпроводниках (ВТСП) экспериментально на основе резистивных измерений $[1,2]$ и прямым наблюдением с помощью магнитооптической техники [3-5]. Моделирование свойств меднооксидных ВТСП также возможно с помощью рассмотрения их фрактальных особенностей [6-8].

Магнитополевые параметры меднооксидных ВТСП зависят по крайней мере от трех факторов: 1) распределения неоднородностей по площадям, 2) изменения границ этих неоднородностей, 3) изменения сети слабых связей во всем образце. Все эти факторы в значительной степени связаны с фрактальными свойствами границ кластеров нормальной фазы. Такие кластеры образуются как при облучении образцов тяжелыми ионами, так и в процессе роста пленок или спекания массивных образцов поликристаллов [8-11].

Особенности кластеров нормальной фазы были подробно рассмотрены в работах [12-15]. В работе [8] было установлено, что на фрактальную размерность границ кластеров нормальной фазы сильно влияет постоянное магнитное поле. Это связано с образованием слабых связей на структурных дефектах, легко образующихся в ВТСП из-за малой длины когерентности в этих материалах. При повышении напряженности поля от 50 до 200 Ое фрактальная размерность увеличивалась от 1.2 до
1.9. Определение фрактальной размерности было сделано с помощью аппроксимации экспериментальных токовых зависимостей первой гармоники напряжения (пропорциональной дифференциальному сопротивлению при малых токах) экспоненциально-гиперболической функцией, параметром которой и была фрактальная размерность.

В настоящей работе исследуется магнитополевая зависимость первой гармоники напряжения при различных транспортных токах. При этом ток является параметром,

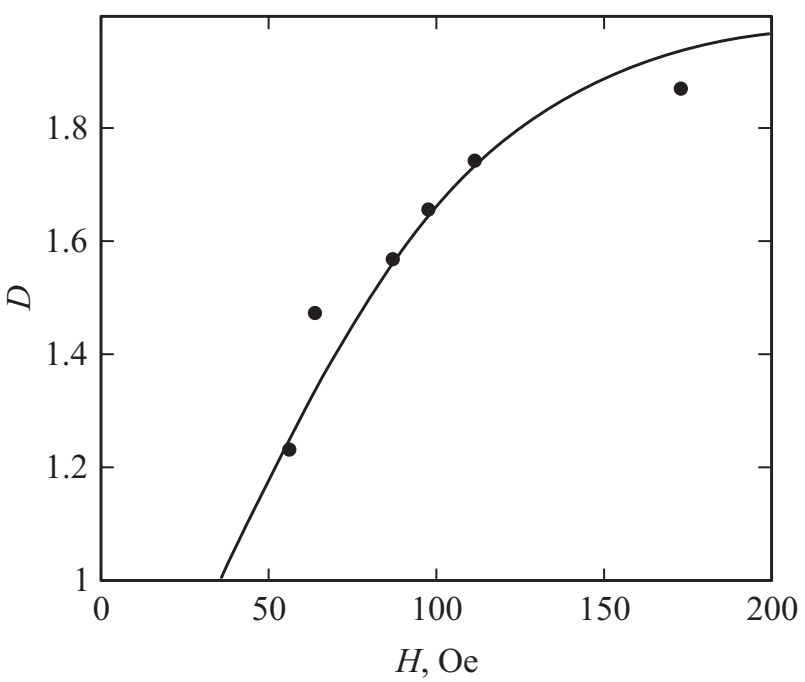

Рис. 1. Зависимость фрактальной размерности кластеров нормальной фазы от напряженности постоянного магнитного поля. Черные круги - данные, полученные в работе [8], сплошная линия - эмпирическая зависимость (формула (1)). 


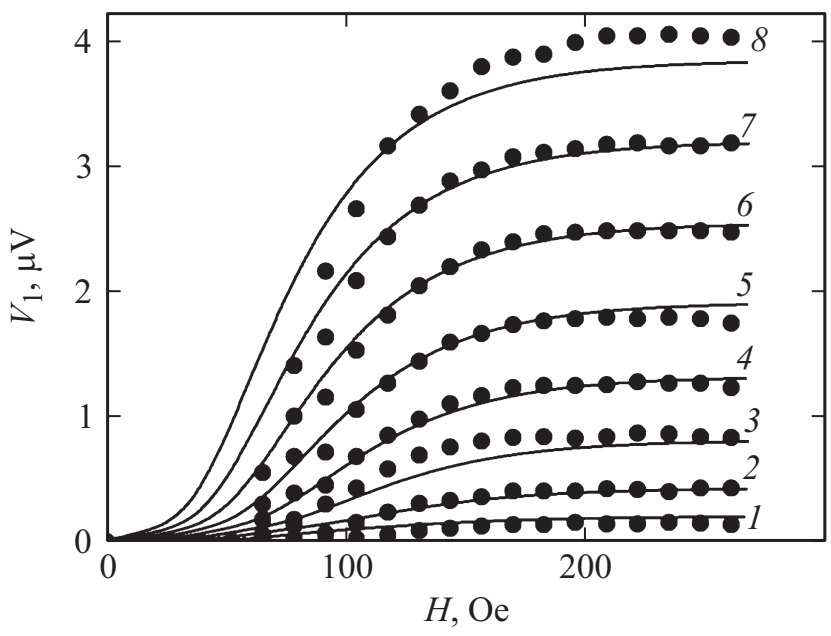

Рис. 2. Магнитополевая зависимость амплитуды первой гармоники напряжения при разных значениях постоянного тока . Черные круги - экспериментальные зависимости, сплошные линии - теоретические кривые, рассчитанные по формуле (2). $I_{d}, \mathrm{~mA}: 1-30,2-40,3-50,4-60,5-70,5-70$, $6-80,7-90,8-100$.

а зависимость от магнитного поля опосредуется фрактальной размерностью границ кластеров нормальной фазы.

Образцы меднооксидного ВТСП $\mathrm{YBa}_{2} \mathrm{Cu}_{3} \mathrm{O}_{7-x}$ (YВСО) были приготовлены стандартным методом твердофазного синтеза исходных оксидов. Плотность поликристаллических образцов $-4.18 \mathrm{~g} / \mathrm{cm}^{3}$. Температура перехода в сверхпроводящее состояние $T_{c} \approx$ $\approx 92.0 \mathrm{~K}$. Ширина перехода $\Delta T_{c} \approx 1.5 \mathrm{~K}$. Исследования проводились при температуре $T \approx 77 \mathrm{~K}$ четырехконтактным методом на переменном токе. Сопротивление контактов $R \approx 3 \mathrm{~m} \Omega$. Подробнее техника измерений изложена в работе [16].

На рис. 1 показана зависимость фрактальной размерности границ кластеров нормальной фазы $D$ от напряженности постоянного магнитного поля $H$. Зависимость $D(H)$, полученная в работе [8] (черные круги), аппроксимирована функцией (сплошная линия):

$$
D=2 /\left[\exp \left(-\left(H-H_{1}\right) / H_{0}\right)+1\right]
$$

где $H_{0}=40 \mathrm{Oе}$ и $H_{1}=36 \mathrm{Oe}-$ напряженности поля, характерные для данного образца.

На рис. 2 изображена экспериментальная зависимость амплитуды первой гармоники напряжения $V_{1}$ на образце YВСО от напряженности магнитного поля (черные круги) для различных значений постоянного тока. Аппроксимация $V_{1}(H)$ сделана с помощью экспоненциально-гиперболической функции, найденной для вольт-амперной характеристики того же образца в работе [8]:

$$
\begin{aligned}
V_{1}= & R_{d} I_{a}=I_{a}\left[R_{d 1} \exp \left(-C_{1} C_{0} i^{-\mu}\right)\right. \\
& \left.+R_{d 2} \exp \left(-C_{2} C_{0} i^{-\mu}\right)\right],
\end{aligned}
$$

где $i=I_{d} / I_{c}-$ безразмерный ток, $I_{d}-$ постоянный ток, $I_{c}=316 \mathrm{~mA}-$ критический ток при $H=0, R_{d}=$ $=\left(d V / d I_{d}\right)-$ дифференциальное сопротивление, $I_{a}=27 \mathrm{~mA}$ - амплитуда переменного тока, $C_{0}=(1+$ $+1 / \mu)^{\mu+1}, \mu=2 / D$ - показатель стекловидности [15], $C_{1}=0.02, C_{2}=0.14, R_{d 1}=0.012 \mathrm{~m} \Omega, R_{d 2}=0.78 \mathrm{~m} \Omega$.

Зависимость $V_{1}(H)$ обусловливается зависимостью от магнитного поля фрактальной размерности $D$, а тем самым и показателя стекловидности $\mu$, значение которого в данном случае находится в пределах от 1 до 2. Это соответствует крипу связок вихрей в образце [15].

Два слагаемых в формуле (2) необходимы из-за количественного различия внутригранулярных и межгранулярных дифференциальных сопротивлений поликристалла. Функции распределения дефектов по площадям и фрактальная размерность их границ не зависят от того, находятся они внутри гранул или между ними.

Величина $R_{d 1}=0.012 \mathrm{~m} \Omega$ в данной аппроксимации уменьшена по сравнению со значением, найденным в работе [8]. Это связано с отсутствием сопротивления при значениях напряженности поля до 50 Ое. Нулевое сопротивление в начале зависимости $V_{1}(H)$ в значительной степени обусловлено образованием гипервихрей в образце [17]. Поэтому начало роста напряжения определяется двумя процессами: распадом гипервихрей на отдельные джозефсоновские вихри и увеличением фрактальной размерности кластеров нормальной фазы с ростом поля.

Для анализа нелинейных динамических систем можно использовать понятие неравновесных квазистационарных состояний, обладающих топологией перколирующего фрактального множества [18]. В этом случае одной из основных характеристик системы является индекс связности $\theta$. На пороге перколяции индекс связности фрактала можно определить по его фрактальной размерности

$$
\theta=2\left(D / d_{s}-1\right)
$$

Здесь $d_{s}-$ спектральная фрактальная размерность.

Так как на пороге перколяции $d_{s}=C \approx 1.327$ [18], то из формулы (3) можно определить значения индекса связности для разных значений фрактальной размерности. В нашем случае (рис. 1) D меняется от 1.2 до 1.9, что соответствует изменению $\theta$ от -0.2 до 1.43 . При $D=C \approx 1.327$ происходит изменение знака индекса связности с минуса на плюс, что означает переход от несвязной системы к связной, т.е. начало перколяции. Это значение фрактальной размерности соответствует напряженности магнитного поля $\approx 60-70$ Ое. Такое значение напряженности поля соответствует началу проникновения вихрей в гранулы поликристалла YВСО. 


\section{Список литературы}

[1] Prester M. // Phys. Rev. B. 1999. Vol. 60. N 5. P. 3100-3103.

[2] Балаев Д.А., Белозерова И.Л., Гохфельд Д.М., Кашкина Л.В., Кузьмин Ю.И., Мигель К.Р., Петров М.И., Попков С.И., Шайхутдинов К.А. // ФТТ. 2006. Т. 48. Вып. 2. C. 193-198.

[3] Surdeanu R., Wijngaarden R.J., Dam B., Recto J., Griessen R., Rossel C., Ren Z. F., Wang J.H. // Phys. Rev. B. 1998. Vol. 58. N 18. P. 12467-12477.

[4] Baziljevich M., Baruch-El E., Johansen T.H., Yeshurun Y. // Appl. Phys. Lett. 2014. Vol. 105. N 1. P. 012602(4).

[5] Vestgården J.I., Mikheenko P., Galperin Y.M., Johansen T.H. // New J. Phys. 2013. Vol. 15. N 9. P. 093001(26).

[6] Milovanov A.V., Rasmussen J.J. // Phys. Rev. B. 2002. Vol. 66. N 13. P. $134505(11)$.

[7] Кузьмин Ю.И. // Письма в ЖТФ. 2014. Т. 40. Вып. 17. C. $94-102$.

[8] Васютин М.А. // Письма в ЖТФ. 2011. Т. 37. Вып. 16. C. $1-6$.

[9] Kang S., Goyal A., Li J., Gapud A.A., Martin P.M., Heatherly L., Thompson J.R., Christen D.K., List F.A., Paranthaman M., Lee D.F. // Science. 2006. Vol. 311. N 5769. P. 1911-1914.

[10] Кузьмин Ю.И., Плешаков И.В., Разумов С.В. // ФТТ. 1999. Т. 41. Вып. 10. С. 1739-1742.

[11] Wee Sung Hun, Goyal Amit, Specht Eliot D., Cantoni Claudia, Zuev Yuri L., Selvamanickam V., Cook Sy. // Phys. Rev. B. 2010. Vol. 81. N 14. P. 140503(4).

[12] Кузьмин Ю.И. // ФТТ. 2001. Т. 43. Вып. 7. С. 1157-1164.

[13] Кузьмин Ю.И. // Письма в ЖТФ. 2004. Т. 30. Вып. 11. C. $29-37$.

[14] Кузьмин Ю.И., Плешаков И.В. // Письма в ЖТФ. 2016. Т. 42. Вып. 3. С. 76-83.

[15] Кузьмин Ю.И. // Письма в ЖТФ. 2010. Т. 36. Вып. 9. C. $17-25$.

[16] Васютин М.А., Кузьмичев Н.Д. // Письма в ЖТФ. 1992. Т. 18. Вып. 23. С. 5-9.

[17] Кузьмичев Н.Д. // ФТТ. 2001. Т. 43. Вып. 11. С. 1934-1938.

[18] Зеленый Л.М., Милованов А.В. // УФН. 2004. Т. 174. № 8. C. $809-852$. 